\title{
$O$ enfermeiro intensivista frente ao paciente potencial doador de órgãos
}

\author{
The intensive nurse in respect of the potential patient organ donor
}

La enfermera de cuidados intensivos frente al paciente potencial donante de órganos

\section{Amanda dos Santos Anacleto ${ }^{1}$, Jorge Luiz Lima da Silva ${ }^{2 *}$, João Victor Lima da Silva ${ }^{3}$, Marisa Augusta Oliveira $^{4}$, Cristhian Antonio Brezolin ${ }^{5}$, Lunna Machado Soares ${ }^{6}$}

Como citar esse artigo. Anacleto, AS; da Silva, JLL; da Silva, JVL; Oliveira, MA; Brezolin, CA; Soares, LM. O enfermeiro intensivista frente ao paciente potencial doador de órgãos. Revista Pró-UniverSUS. 2020 Jul./Dez.; 11 (2): 89-96.

\section{Resumo}

Objetivo: descrever os cuidados de enfermagem na manutenção do potencial doador de órgão e tecidos na Unidade de Terapia Intensiva. Material e método: pesquisa descritiva, realizada por meio de revisão bibliográfica, baseada em obras publicadas entre 2010 e 2020. Resultados: o enfermeiro exerce atuação na identificação e manutenção das funções vitais do doador, mas para isto, é necessário conhecimento técnico e cientifico sobre o assunto, na busca foram encontrados 8 estudos que se adequava a temática. Discussão: estabilizar hemodinamicamente, corrigir o déficit de oxigenação, tratar infecções bacterianas, reverter à hipotermia, são alguns dos principais cuidados de enfermagem frente à situação descrita. Conclusões: há necessidade de execução de atividades educativas junto aos profissionais de enfermagem. Além da identificação, confirmação, prevenção, detecção precoce e manuseio imediato das complicações advindas da morte encefálica, para que os órgãos possam ser retirados e transplantados nas melhores condições funcionais possíveis.

Palavras-chave: Transplante de Órgãos; Cuidados De Enfermagem; Unidade De Terapia intensiva.

\begin{abstract}
Objective: to describe nursing care in maintaining the potential organ and tissue donor in the Intensive Care Unit. Material and method: descriptive research, carried out through a bibliographic review, based on works published between 2010 and 2020. Results: the nurse acts in the identification and maintenance of the donor's vital functions, but for this, technical and scientific knowledge is necessary on the subject, 8 studies were found in the search that suited the theme. Discussion: stabilize hemodynamically, correct the deficit of oxygenation, treat bacterial infections, revert to hypothermia, are some of the main nursing care given the situation described. Conclusions: there is a need to carry out educational activities with nursing professionals. In addition to the identification, confirmation, prevention, early detection and immediate handling of complications from brain death, so that the organs can be removed and transplanted in the best possible functional conditions.
\end{abstract}

Keywords: Organ Transplantation; Nursing Care; Intensive Care Unit.

\section{Resumen}

Objetivo: describir la atención de enfermería en el mantenimiento del donante potencial de órganos y tejidos en la Unidad de Cuidados Intensivos. Material y método: investigación descriptiva, realizada a través de una revisión bibliográfica, basada en trabajos publicados entre 2010 y 2020. Resultados: la enfermera actúa en la identificación y mantenimiento de las funciones vitales del donante, pero para ello, se necesitan conocimientos técnicos y científicos. sobre el tema, se encontraron 8 estudios en la búsqueda que se ajustaba al tema. Discusión: estabilizar hemodinámicamente, corregir el déficit de oxigenación, tratar infecciones bacterianas, revertir a hipotermia, son algunos de los principales cuidados de enfermería dada la situación descrita. Conclusiones: es necesario realizar actividades educativas con profesionales de enfermería. Además de la identificación, confirmación, prevención, detección temprana y manejo inmediato de las complicaciones de la muerte cerebral, para que los órganos puedan extraerse y trasplantarse en las mejores condiciones funcionales posibles.

Palabras clave: Trasplante de Órganos; Cuidados de Enfermería; Unidad de Cuidados Intensivos.

Afiliação dos autores:

${ }^{1}$ Universidade Federal Fluminense/Niterói/ Rio de Janeiro/ Brasil. ORCID: https://orcid.org/0000-0002-2875-6550

${ }^{2}$ Docente. Universidade Federal Fluminense/Niterói/ Rio de Janeiro/ Brasil. ORCID: https://orcid.org/0000-0002-2370-6343

${ }^{3}$ Universidade Federal Fluminense/Niterói/ Rio de Janeiro/ Brasil. ORCID: https://orcid.org/0000-0002-5561-0303

${ }^{4}$ Universidade Federal Fluminense/Niterói/ Rio de Janeiro/ Brasil. ORCID· https///orcid org/0000-0003-4687-3168

${ }^{5}$ Universidade Federal Fluminense/Niterói/ Rio de Janeiro/ Brasil. ORCID: https://orcid.org/0000-0002-9525-2459

${ }^{6}$ Universidade Federal Fluminense/Niterói/ Rio de Janeiro/ Brasil. ORCID: https://orcid.org/0000-0002-2842-6295 


\section{Introdução}

O transplante de órgãos é, em muitos casos, a única alternativa terapêutica em pacientes portadores de disfunções terminais de diferentes órgãos essenciais. Apesar do crescente aumento no número de doações, nota-se, nos últimos anos, uma preocupante desproporção entre a demanda e o número de transplantes realizados ${ }^{1}$.

O Brasil é o segundo colocado em número de transplantes absolutos realizados anualmente entre os 35 países que mais transplantam no mundo, sendo mais de 90\% efetuados pelo Sistema Único de Saúde (SUS). Os doadores vivos podem doar medula óssea, um dos rins, parte do fígado e do pulmão. Já os doadores falecidos, com diagnóstico de morte encefálica possibilitam a doação de coração, pulmões, rins, córneas, fígado, pâncreas, ossos, tendões, veias e intestino ${ }^{2}$.

Em 2018, foi registrado o maior número de doadores efetivos da história da nação: 3.531. O número representa uma taxa de 17,0 por milhão da população (PMP), 2,4\% maior em comparação a 2017. Além disso, registrou-se crescimento de $48,9 \%$ no número de potenciais doadores (PD) entre 2011 e 2018, passando de 7.238 para $10.779^{3}$.

O sucesso da doação de órgãos depende de um processo dinâmico, realizado através de várias etapas interligadas. O procedimento envolve desde a detecção precoce do PD até o acompanhamento de resultados pós-transplante. No país, a captação e doação de órgãos é regulada e normatizada pela lei $\mathrm{n}^{\circ}$ 9.434/97, regulamentada pelo Decreto Lei $\mathrm{n}^{\circ} 9.175$ de 2017, os quais estabelecem as diretrizes da Política Nacional de Transplantes de Órgãos e Tecidos, determinando a gratuidade da doação, bem como os critérios para seleção do PD vivo ou falecido ${ }^{4}$.

Existem três tipos de PD falecidos: doador com coração parado recente, do qual é possível a retirada de órgãos e tecidos, cujo procedimento deve ser imediato; doador com coração parado tardio, nesse caso, podendo ser doados apenas tecidos, com retirada no prazo de $6 \mathrm{~h}$ após a parada cardiorrespiratória e até $24 \mathrm{~h}$ se o corpo do doador estiver refrigerado; e, doador diagnosticado com Morte Encefálica (ME), podendo doar todos os órgãos e tecidos ${ }^{5}$.

O papel da enfermagem diante de paciente em ME na Unidade de Terapia Intensiva (UTI) deve ser desempenhado com dignidade e respeito, independentemente do procedimento a ser realizado. É primordial ter conhecimentos científicos a respeito da fisiopatologia, pois tal profissional exerce função extremamente importante no controle de todos os dados hemodinâmicos, hídricos e monitorização dos pacientes. Esses procedimentos são necessários para que a doação ocorra de maneira satisfatória ${ }^{2}$. O enfermeiro deve estar capacitado a identificar tais alterações fisiopatológicas para que, junto com a equipe de saúde, possa instituir medidas terapêuticas adequadas.

Considerando que a enfermagem assume responsabilidade natural de cuidados aos pacientes nestas condições, há uma tendência de menor investimento em cuidados por parte da equipe de enfermagem, principalmente quando não há definição sobre a doação .

Diante ao exposto, o estudo teve por objetivo descrever os cuidados de enfermagem na UTI frente à manutenção do PD de órgãos e tecidos. Com isso, pretende-se contribuir para maior discussão sobre a temática, diante da escassez de conteúdo específicos nessa área.

\section{Material e Método}

A pesquisa de natureza descritiva foi elaborada por meio de revisão bibliográfica baseada em obras secundárias que abordam o tema Cuidados de Enfermagem na manutenção de um PD de órgão e tecidos na UTI, publicadas no período de 2010 a 2020 em periódicos de enfermagem do Brasil, cuja coleta do material se deu em maio de 2020.

O levantamento foi realizado em ambiente virtual na Biblioteca Virtual de Saúde (BVS), nas bases: Literatura Latino-Americana e do Caribe em Ciências da Saúde (Lilacs), Base de Dados de Enfermagem (Bdenf), Scientific Electronic Library Online (Scielo), com busca livre, dada a escassez de trabalhos sobre o assunto, de textos completos, a partir dos seguintes termos de busca: "Transplantes de órgãos", "Cuidados de enfermagem" e "Unidade de Terapia Intensiva". Esses termos foram utilizados de forma conjunta e isolados.

Inicialmente, foi realizada pré-seleção, conforme a leitura dos resumos. Nessa fase, buscou-se a relação entre o conteúdo, título, resumo, e se atendiam ao objeto do presente estudo. Na fase de seleção, as obras foram lidas na íntegra. Os trabalhos que não apresentavam qualquer relação com o objeto de estudo e aquelas em duplicidade foram excluídos, considerando-se o primeiro registro.

Tendo em vista que o objetivo da pesquisa foi descrever os cuidados de enfermagem na UTI frente à manutenção do PD de órgãos e tecidos, no Brasil, que estavam disponíveis para leitura de forma completa, conforme descritos na tabela 1. Ao utilizar os termos de busca, foram encontrados 56 artigos, oito se adequavam aos parâmetros estabelecidos, foram descartados 48 artigos, por não caracterizarem os sujeitos estudados de acordo com o objetivo.

Realizada a triagem das obras foram obtidos oito artigos, dois livros para embasamento teórico, um arquivo de outras categorias (1 manual). Depois das etapas descritas, foram construídos nos resultados itens que abordam os cuidados de enfermagem na UTI frente 
Tabela 1. Distribuição dos artigos de acordo com os periódicos selecionados em ambiente da BVS no período de 2010 a 2020.'

\begin{tabular}{|c|c|c|c|c|c|c|c|c|c|c|c|c|}
\hline \multirow{2}{*}{ PERIÓDICOS } & \multicolumn{12}{|c|}{ ANO DE PUBLICAÇÃO } \\
\hline & 2010 & 2011 & 2012 & 2013 & 2014 & 2015 & 2016 & 2017 & 2018 & 2019 & 2020 & Total \\
\hline Rev. Eletronic. & 1 & - & 1 & - & - & - & - & - & - & - & - & 2 \\
\hline Enferm. & & & & & & & & & & & & \\
\hline J. Health Sci. Inst. & - & - & 1 & - & - & - & - & - & - & - & - & 1 \\
\hline Cuid Arte & - & - & - & - & 1 & - & - & - & - & - & - & 1 \\
\hline Enferm. Foco & - & - & - & - & - & 1 & - & - & - & - & - & 1 \\
\hline Nursing (SP) & - & - & - & - & - & 1 & - & - & - & - & - & 1 \\
\hline Rev. Bioética & - & - & - & - & - & - & 1 & - & - & - & - & 1 \\
\hline Enferm. Global & - & - & - & - & - & - & - & - & - & 1 & - & 1 \\
\hline Total & 1 & - & 2 & - & 1 & 2 & 1 & - & - & 1 & - & 8 \\
\hline
\end{tabular}

à manutenção do PD de órgãos e tecidos.

\section{Resultados}

A partir de dados coletados, dos cinco artigos utilizados na elaboração deste estudo, contatou-se que o enfermeiro exerce atuação na identificação e
Fonte: Elaboração própria

manutenção das funções vitais do doador, mas para isto é necessário que haja conhecimento técnico e científico, principalmente sobre as alterações fisiopatológicas da ME e a importância de programas de educação permanente para a capacitação profissional da equipe. Um quadro foi construído para possibilitar ao leitor uma melhor compreensão das obras.

Quadro 1. Publicações selecionadas nas bases Lilacs, Bdenf e Scielo, publicadas nos últimos 10 anos.

\begin{tabular}{|c|c|c|c|c|c|c|}
\hline AUTORES & ANO & PERIÓDICO & $\begin{array}{c}\text { OBJETIVO DA } \\
\text { PESQUISA }\end{array}$ & MÉTODO & $\begin{array}{c}\text { PRINCIPAIS } \\
\text { ACHADOS }\end{array}$ & $\begin{array}{c}\text { CONCLUSÃO } \\
\text { DO ARTIGO }\end{array}$ \\
\hline $\begin{array}{l}\text { MendonçaAles- } \\
\text { sandra Santana, } \\
\text { Castro Dayana } \\
\text { Clênia, Brasi- } \\
\text { leiro Marislei } \\
\text { Espíndola }\end{array}$ & 2010 & $\begin{array}{l}\text { RevistaEletrônica } \\
\text { de Enfermagem. }\end{array}$ & $\begin{array}{l}\text { Identificar a atuação } \\
\text { do enfermeiro na as- } \\
\text { sistência dispensada } \\
\text { ao PD de múltiplos } \\
\text { órgãos. }\end{array}$ & $\begin{array}{l}\text { Estudo do tipo } \\
\text { Bibliográfico, } \\
\text { descritivo-explo- } \\
\text { ratório e retros- } \\
\text { pectivo com aná- } \\
\text { lise integrativa, } \\
\text { sistematizada e } \\
\text { qualitativa. }\end{array}$ & $\begin{array}{l}\text { É necessário que } \\
\text { enfermeiro conheça } \\
\text { as alterações fisio- } \\
\text { patológicas da ME } \\
\text { para estabelecer os } \\
\text { cuidados e identificar } \\
\text { como é realizada. }\end{array}$ & $\begin{array}{l}\text { O enfermeiro deve } \\
\text { ser capacitado a reco- } \\
\text { nhecer as alterações } \\
\text { decorrentes da morte } \\
\text { encefálica para que, } \\
\text { possa conduzir de } \\
\text { maneira } \\
\text { adequada às medidas } \\
\text { terapêuticas, visando } \\
\text { a melhor evolução do } \\
\text { transplantado. }\end{array}$ \\
\hline $\begin{array}{lr}\text { Freire } & \text { Izaura } \\
\text { Luzia } & \text { Silvério } \\
\text { et al. } & \end{array}$ & 2012 & $\begin{array}{l}\text { Rev. Eletrônic. } \\
\text { Enf. }\end{array}$ & $\begin{array}{l}\text { Avaliar o conheci- } \\
\text { mento dos profis- } \\
\text { sionais de enferma- } \\
\text { gem relacionados à } \\
\text { Morte encefálica e } \\
\text { aos cuidados na ma- } \\
\text { nutenção do PD de } \\
\text { órgãos e tecidos para } \\
\text { transplante. }\end{array}$ & $\begin{array}{l}\text { Estudo explora- } \\
\text { tório-descritivo } \\
\text { com abordagem } \\
\text { quantitativa. }\end{array}$ & $\begin{array}{l}\text { Ao retratar a impor- } \\
\text { tância de programas } \\
\text { de educação perma- } \\
\text { nente, a equipe de } \\
\text { enfermagem é citada } \\
\text { como elemento fun- } \\
\text { damental em todo o } \\
\text { contexto do proce- } \\
\text { dimento, uma vez } \\
\text { que a aprendizagem } \\
\text { significa mudança } \\
\text { no comportamento } \\
\text { da pessoa devido à } \\
\text { incorporação de no- } \\
\text { vos hábitos, atitudes, } \\
\text { conhecimentos e des- } \\
\text { trezas. }\end{array}$ & $\begin{array}{l}\text { O conhecimento prá- } \\
\text { tico e científico atual } \\
\text { sobre os cuidados de } \\
\text { manutenção ao PD, } \\
\text { no que se refere aos } \\
\text { profissionais de en- } \\
\text { fermagem, é insufi- } \\
\text { ciente e superficial. }\end{array}$ \\
\hline
\end{tabular}


Quadro 1 (cont.). Publicações selecionadas nas bases Lilacs, Bdenf e Scielo, publicadas nos últimos 10 anos.

\begin{tabular}{|c|c|c|c|c|c|c|}
\hline AUTORES & ANO & PERIÓDICO & $\begin{array}{c}\text { OBJETIVO DA } \\
\text { PESQUISA }\end{array}$ & MÉTODO & $\begin{array}{l}\text { PRINCIPAIS } \\
\text { ACHADOS }\end{array}$ & $\begin{array}{c}\text { CONCLUSÃO } \\
\text { DO ARTIGO }\end{array}$ \\
\hline $\begin{array}{l}\text { Guimarães, Jus- } \\
\text { sara Borges } \\
\text { Barbosa, Naia- } \\
\text { ne Moreira } \\
\text { Batista, Mira- } \\
\text { nildes de Abreu } \\
\text { Passos, Xisto } \\
\text { Sena }\end{array}$ & 2012 & $\begin{array}{l}\text { J. Health Sci. } \\
\text { Inst. }\end{array}$ & $\begin{array}{l}\text { Verificar o conhe- } \\
\text { cimento dos enfer- } \\
\text { meiros da Unidade } \\
\text { de Terapia Intensiva } \\
\text { (UTI) do Hospital de } \\
\text { Urgências de Goi- } \\
\text { ânia-GO (HUGO), } \\
\text { sobre condutas de } \\
\text { enfermagem a serem } \\
\text { tomadas no manejo } \\
\text { do potencial doador } \\
\text { de órgãos, no que se } \\
\text { refere à prevenção, } \\
\text { manutenção e con- } \\
\text { trole da temperatura. }\end{array}$ & $\begin{array}{l}\text { Realizou-se uma } \\
\text { pesquisa quantita- } \\
\text { tiva, do tipo explo- } \\
\text { ratório e descri- } \\
\text { tivo, no Hospital } \\
\text { de Urgências de } \\
\text { Goiânia, Goiás. } \\
\text { Participaram } 10 \\
\text { enfermeiros atu- } \\
\text { antes em Unidade } \\
\text { de Terapia Inten- } \\
\text { siva. }\end{array}$ & $\begin{array}{l}\text { Constatou-se que os } \\
\text { enfermeiros parti- } \\
\text { cipantes conhecem } \\
\text { diversas estratégias } \\
\text { no manejo da queda } \\
\text { de temperatura que } \\
\text { acomete o paciente } \\
\text { em morte encefálica, } \\
\text { o que contribui para } \\
\text { a otimização do pro- } \\
\text { cesso de transplan- } \\
\text { tes. Identificou-se as } \\
\text { condutas de enfer- } \\
\text { magem utilizadas na } \\
\text { manutenção da tem- } \\
\text { peratura corporal do } \\
\text { potencial doador de } \\
\text { órgãos. }\end{array}$ & $\begin{array}{l}\text { Diante dos resul- } \\
\text { tados apresentados } \\
\text { verificou-se que o } \\
\text { enfermeiro conhece } \\
\text { a importância da ma- } \\
\text { nutenção da tempe- } \\
\text { ratura corporal para } \\
\text { o potencial doador } \\
\text { de órgãos e também } \\
\text { a necessidade de se } \\
\text { prevenir complica- } \\
\text { ções que podem con- } \\
\text { tribuir para inviabili- } \\
\text { zar a doação. }\end{array}$ \\
\hline $\begin{array}{l}\text { Araujo, Jhonna- } \\
\text { than Pablo Mar- } \\
\text { ques de } \\
\text { Aguiar, Valéria } \\
\text { Monteiro } \\
\text { Amaral, Tha- } \\
\text { tiana Lameira } \\
\text { Maciel } \\
\text { Genzini, Tércio } \\
\text { Prado, Patrícia } \\
\text { Rezende do. }\end{array}$ & 2014 & $\begin{array}{l}\text { CuidArte, En- } \\
\text { ferm. }\end{array}$ & $\begin{array}{l}\text { Realizar uma revisão } \\
\text { sistemática sobre as } \\
\text { principais alterações } \\
\text { fisiopatológicas do } \\
\text { potencial doador } \\
\text { em morte encefálica } \\
\text { e elencar os cuida- } \\
\text { dos de enfermagem } \\
\text { a serem prestados } \\
\text { na manutenção de } \\
\text { múltiplos órgãos do } \\
\text { potencial doador em } \\
\text { Unidade de Terapia } \\
\text { Intensiva. }\end{array}$ & $\begin{array}{l}\text { Foi realizada } \\
\text { uma revisão nas } \\
\text { bases de dados } \\
\text { da Enfermagem } \\
\text { (BDENF), Litera- } \\
\text { tura Internacional } \\
\text { em Ciências e } \\
\text { Saúde (Medline), } \\
\text { National Libra- } \\
\text { ry of Medicine } \\
\text { and the National } \\
\text { Institute of He- } \\
\text { alth (Pubmed), } \\
\text { Cumulative Index } \\
\text { to Nursing Allied } \\
\text { Health Literature } \\
\text { (Cinahl) com os } \\
\text { descritores: trans- } \\
\text { plante, cuidados } \\
\text { de enfermagem, } \\
\text { potencial doador } \\
\text { e alterações fisio- } \\
\text { lógicas. }\end{array}$ & $\begin{array}{l}\text { Foram encontrados } \\
17 \text { artigos e um ma- } \\
\text { nual, os quais foram } \\
\text { organizados em te- } \\
\text { mas: Diagnóstico de } \\
\text { Morte Encefálica, } \\
\text { Alterações Fisiopa- } \\
\text { tológicas inerentes } \\
\text { à morte encefálica } \\
\text { (alterações cardio- } \\
\text { vasculares, pulmona- } \\
\text { res, de temperatura e } \\
\text { endócrinas) e os res- } \\
\text { pectivos cuidados de } \\
\text { enfermagem. }\end{array}$ & $\begin{array}{l}\text { Com conhecimento } \\
\text { técnico e científico, } \\
\text { é possível prestar } \\
\text { melhor assistência } \\
\text { aos potenciais doa- } \\
\text { dores, contribuindo } \\
\text { assim para melhorar } \\
\text { o cenário dos trans- } \\
\text { plantes. }\end{array}$ \\
\hline $\begin{array}{l}\text { Doria, Danielle } \\
\text { Lino } \\
\text { Leite, Paula } \\
\text { Mara Gomes } \\
\text { Brito, Fabiana } \\
\text { Pereira Guima- } \\
\text { rães } \\
\text { Brito, Gabriela } \\
\text { Menezes Gon- } \\
\text { çalves } \\
\text { Resende, Ga- } \\
\text { bryella Garibal- } \\
\text { de Santana } \\
\text { Santos, Fábia } \\
\text { Luanna Leite } \\
\text { Siqueira Men- } \\
\text { des. }\end{array}$ & 2015 & $\begin{array}{l}\text { Enferm. foco } \\
\text { (Brasília). }\end{array}$ & $\begin{array}{l}\text { Verificar o conheci- } \\
\text { mento do enfermeiro } \\
\text { no processo de doa- } \\
\text { ção de órgãos e teci- } \\
\text { dos para transplan- } \\
\text { tes, em um Hospital } \\
\text { Geral de Sergipe. }\end{array}$ & $\begin{array}{l}\text { Estudo transver- } \\
\text { sal, descritivo, } \\
\text { quantitativo, rea- } \\
\text { lizado através de } \\
\text { entrevistas com } \\
45 \text { enfermeiros } \\
\text { das unidades de } \\
\text { terapia intensiva e } \\
\text { emergência. }\end{array}$ & $\begin{array}{l}\text { Estudo transversal, } \\
\text { descritivo, quantitati- } \\
\text { vo, realizado através } \\
\text { de entrevistas com } \\
45 \text { enfermeiros das } \\
\text { unidades de terapia } \\
\text { intensiva e emergên- } \\
\text { cia. }\end{array}$ & $\begin{array}{l}\text { Os enfermeiros apre- } \\
\text { sentaram considerá- } \\
\text { vel conhecimento em } \\
\text { relação ao processo } \\
\text { de doação, e baixo } \\
\text { em relação a manu- } \\
\text { tenção do potencial } \\
\text { doador. (AU) }\end{array}$ \\
\hline
\end{tabular}


Quadro 1 (cont.). Publicações selecionadas nas bases Lilacs, Bdenf e Scielo, publicadas nos últimos 10 anos.

\begin{tabular}{|c|c|c|c|c|c|c|}
\hline AUTORES & ANO & PERIÓDICO & $\begin{array}{c}\text { OBJETIVO DA } \\
\text { PESQUISA }\end{array}$ & MÉTODO & $\begin{array}{c}\text { PRINCIPAIS } \\
\text { ACHADOS }\end{array}$ & $\begin{array}{c}\text { CONCLUSÃO } \\
\text { DO ARTIGO }\end{array}$ \\
\hline $\begin{array}{l}\text { Oliveira, Maria } \\
\text { Jocely Rodri- } \\
\text { gues de Lima } \\
\text { Morais Júnior, } \\
\text { Sérgio Luis Al- } \\
\text { ves de. }\end{array}$ & 2015 & $\begin{array}{l}\text { Nursing } \quad \text { (Säo } \\
\text { Paulo). }\end{array}$ & $\begin{array}{l}\text { Apresentar os aspec- } \\
\text { tos religiosos envol- } \\
\text { vidos no processo de } \\
\text { doação de órgãos e } \\
\text { como o enfermeiro } \\
\text { pode intervir. }\end{array}$ & $\begin{array}{l}\text { Revisão de litera- } \\
\text { tura }\end{array}$ & $\begin{array}{l}\text { O processo de mor- } \\
\text { te e morrer tem suas } \\
\text { particularidades reli- } \\
\text { giosas e o enfermei- } \\
\text { ro serve como ponte } \\
\text { nesta fase. }\end{array}$ & $\begin{array}{l}\text { Incluindo a captação } \\
\text { e a manutenção do } \\
\text { potencial doador, e } \\
\text { para tal, precisa co- } \\
\text { nhecer os aspectos } \\
\text { religiosos para ga- } \\
\text { rantir que o mesmo } \\
\text { seja findado com o } \\
\text { máximo de êxito en- } \\
\text { tre os envolvidos. }\end{array}$ \\
\hline $\begin{array}{l}\text { Costa Carlane } \\
\text { Rodrigues, Cos- } \\
\text { ta Luana Pereira } \\
\text { e Aguiar Nicoly }\end{array}$ & 2016 & Rev. Bioética. & $\begin{array}{l}\text { Identificar o papel } \\
\text { da equipe de enfer- } \\
\text { magem nos cuidados } \\
\text { prestados aos pacien- } \\
\text { tes em ME nas UTIs, } \\
\text { apontando condutas } \\
\text { indispensáveis à } \\
\text { ma } \neg \text { nutenção do PD, } \\
\text { assistência à família } \\
\text { e controle de todas } \\
\text { as funções vitais até } \\
\text { o momento da doa- } \\
\text { ção de órgãos. }\end{array}$ & $\begin{array}{l}\text { Revisão biblio- } \\
\text { gráfica, e méto- } \\
\text { do exploratório, } \\
\text { incluindo artigos } \\
\text { de periódicos ele- } \\
\text { trônicos e obras } \\
\text { literárias. }\end{array}$ & $\begin{array}{l}\text { A equipe de enfer- } \\
\text { magem desempenha } \\
\text { pa } \neg \text { pel importante } \\
\text { na manutenção das } \\
\text { funções vitais do PD, } \\
\text { mas para isso é ne- } \\
\text { cessário que te } \neg \text { nha } \\
\text { conhecimento cien- } \\
\text { tífico e técnico a } \\
\text { respeito de todos os } \\
\text { aspectos da ME. }\end{array}$ & $\begin{array}{l}\text { A equipe intensivista } \\
\text { desempenha papel } \\
\text { de grande relevância } \\
\text { na manutenção das } \\
\text { funções vitais do PD, } \\
\text { sendo necessário em- } \\
\text { basamento a respeito } \\
\text { de todos os aspectos } \\
\text { da ME, conhecimen- } \\
\text { to científico e ético. }\end{array}$ \\
\hline $\begin{array}{l}\text { Menna Barreto, } \\
\text { Luciana Nabin- } \\
\text { ger } \\
\text { Chies, Natália } \\
\text { Cabral, Éder } \\
\text { Marques } \\
\text { Nomura, Aline } \\
\text { Tsuna G } \\
\text { Almeida, Mi- } \\
\text { riam de Abreu }\end{array}$ & 2019 & Enferm. glob. & $\begin{array}{l}\text { Identificar na litera- } \\
\text { tura possíveis carac- } \\
\text { terísticas definidoras } \\
\text { para a proposta de } \\
\text { diagnóstico Síndro- } \\
\text { me do equilíbrio fi- } \\
\text { siológico prejudica- } \\
\text { do para pacientes em } \\
\text { morte encefálica e } \\
\text { potenciais doadores } \\
\text { de órgãos. }\end{array}$ & $\begin{array}{l}\text { Revisão integra- } \\
\text { tiva da literatura } \\
\text { incluindo artigos } \\
\text { publicados entre } \\
1997 \text { e } 2017 \text { nas } \\
\text { bases de dados } \\
\text { Web of Science, } \\
\text { LILACS e Pub- } \\
\text { Med. }\end{array}$ & $\begin{array}{l}\text { A amostra foi cons- } \\
\text { tituída por } 37 \text { artigos } \\
\text { identificando } 44 \text { pos- } \\
\text { síveis características } \\
\text { definidoras para o } \\
\text { diagnóstico de enfer- } \\
\text { magem em desenvol- } \\
\text { vimento. As caracte- } \\
\text { rísticas definidoras } \\
\text { foram divididas em } \\
\text { cinco grandes grupos: } \\
\text { alterações endócrino- } \\
\text { metabólicas, altera- } \\
\text { ções hemodinâmicas } \\
\text { e/ou cardiovascula- } \\
\text { res, alterações ven- } \\
\text { tilatórias, alterações } \\
\text { nutricionais e altera- } \\
\text { ções de coagulação, } \\
\text { inflamatórias e/ou } \\
\text { imunológicas. }\end{array}$ & $\begin{array}{l}\text { O desenvolvimen- } \\
\text { to deste diagnóstico } \\
\text { pode colaborar com } \\
\text { a qualificação da ta- } \\
\text { xonomia da NANDA } \\
\text { International, além } \\
\text { de ampliar o conhe- } \\
\text { cimento da enferma- } \\
\text { gem na área de manu- } \\
\text { tenção do potencial } \\
\text { doador de órgãos } \\
\text { contribuindo para o } \\
\text { ensino e pesquisa. O } \\
\text { uso desta proposta de } \\
\text { diagnóstico na práti- } \\
\text { ca pode proporcionar } \\
\text { uma melhor sistema- } \\
\text { tização do cuidado, } \\
\text { auxiliando a adequa- } \\
\text { da manutenção do } \\
\text { potencial doador e } \\
\text { consequentemente } \\
\text { melhor viabilidade } \\
\text { dos órgãos ofertados } \\
\text { para transplantes. }\end{array}$ \\
\hline
\end{tabular}

Fonte: Elaboração própria

\section{Discussão}

A ME é a condição irreversível das funções do encéfalo e tronco encefálico, ocasionada por lesões graves, como acidente vascular encefálico (AVE) isquêmico ou hemorrágico, tumores, anóxia prolongada, trauma crânio encefálico (TCE) e outros, cujos critérios do diagnóstico da morte encefálica são definidos pela Resolução n 2.173 de 2017 do Conselho Federal de
Medicina ${ }^{7}$.

Essa resolução estabelece a obrigatoriedade do cumprimento de no mínimo dois exames clínicos, a serem realizados por dois médicos diferentes, capacitados na determinação de morte encefálica, em que um deles deverá ter especialidade em medicina de emergência, neurologia e medicina intensiva; teste de apneia, que constate a ausência de função respiratória e exame complementar que comprove a ausência de 
atividade elétrica cerebral, sendo os mais comuns: doppler transcraniano, eletroencefalograma (EEG) e arteriografia cerebral 7 .

Os exames clínicos e complementares têm como finalidade comprovar a ausência de reflexos do tronco encefálico, respeitados os intervalos de tempo conforme a idade do possível doador. Entre $1^{\circ}$ e $2^{\circ}$ exame, o intervalo mínimo deverá ser de 1 (uma) hora, em pacientes com idade igual ou maior a 2 (dois) anos. $\mathrm{Na}$ faixa etária de 7 dias a 2 meses incompletos, o mínimo de 24 horas; de 2 a 24 meses incompletos, de 12 horas? Vale ressaltar, que o diagnóstico de ME é proibitivo para médicos que atuem nas equipes de transplantes, por questões éticas e conflito de interesses ${ }^{4}$.

É facultado ao profissional de enfermagem realizar entrevista familiar em relação à doação de órgãos e tecidos após a comunicação da morte encefálica à família. Deve-se esclarecer, de maneira ética e respeitosa, o processo de captação e distribuição dos órgãos e tecidos a serem doados, respeitando-se as opiniões dos familiares e seu momento de perda e dor. Em estado de choque, vivenciando situação de pesar, sofrimento e desespero, a família acredita que o ente ainda possa voltar à vida, devido à conservação de sua temperatura, funções cardíacas e respiratórias através das drogas e equipamentos. Nessas circunstâncias dolorosas, deve ser ofertado à família, acolhimento e apoio psicológico ${ }^{2}$.

Porém, para garantir a efetividade da doação é importante a adequada manutenção e preservação hemodinâmica e fisiológica dos órgãos, do início ao fim do processo. Para isso, são necessários materiais e equipamentos especializados, bem como profissionais capacitados à identificação e controle de todas as alterações apresentadas pelo paciente, ressaltando-se ainda a importância do preparo da equipe para agir, quando for necessária rápida intervenção ${ }^{8}$.

Compete ao enfermeiro, conhecer as alterações fisiopatológicas decorrentes da ME para que, junto à equipe multiprofissional, possa conduzir os cuidados e atuar adequadamente no manuseio do $\mathrm{PD}$, mantendo os órgãos viáveis para o transplante, assim a sua equipe de enfermagem deverá está capacitada à investigação e detecção dessas possíveis complicações tais como infecções, disfunções cardíacas, metabólicas, endócrinas e hematológicas ${ }^{6}$.

Ao ser capacitado a reconhecer as alterações decorrentes da morte encefálica, o enfermeiro poderá conduzir de maneira adequada às medidas terapêuticas, visando a melhor evolução do transplantado.

O enfermeiro intensivista deverá avaliar e registrar em prontuário os sinais vitais; prestar os cuidados com as córneas, as umedecendo com solução fisiológica a $0,9 \%$; higienização corporal no intuito de minimizar riscos de infecção; observar o aspecto e anotar os valores glicêmicos e débito urinário; administrar e avaliar dietas e medicamentos, conforme prescriçáo medica?.

Após a ME, ocorrem mudanças no organismo devido às disfunções fisiológicas e endócrinometabólicas. Os primeiros cuidados englobam avaliação das prescrições medicamentosas relativa ao quadro neurológico, mudança de decúbito, elevação da cabeceira a 30 graus, realizar a aspiração, a fim de fluidificar secreções pulmonares, controle térmico, avaliações periódicas dos acessos, cateteres e mensuração dos sinais vitais em um período nas 24 horas $^{6}$.

É fundamental uma ação rápida e agressiva das medidas de manutenção para garantir a oferta tecidual de oxigênio, visando manter as funções orgânicas de acordo com os indicadores terapêuticos, prevenir e reverter oportunamente e de maneira coordenada eventuais disfunções orgânicas; estabilizar hemodinamicamente; corrigir o déficit de oxigenação; tratar infecções bacterianas; reverter a hipotermia; monitorar e corrigir distúrbios de coagulação, endócrinos e/ou metabólicos passíveis de reversão ${ }^{10,11}$.

A hipovolemia é a principal causa da instabilidade hemodinâmica no PD e a reposição volêmica agressiva é a primeira medida a ser utilizada em casos de PAS $<100 \mathrm{mmHg}$ ou PAM $<65 \mathrm{mmHg}$ em adultos ${ }^{7}$, contar com métodos de monitorização que permitam reconhecer o déficit volêmico com precisão e agilidade é fundamental para minimizar danos teciduais relacionados ao hipofluxo. Nesses casos, o enfermeiro deverá anotar e infundir de 20 a $30 \mathrm{ml} / \mathrm{kg}$ de cristalóide (aquecido a $43^{\circ} \mathrm{C}$ ) em 30 minutos. Essa é a primeira conduta para controle da pressão arterial. As infusões subsequentes deverão ser baseadas em parâmetros metabólicos de oxigenação, e na avaliação da responsividade ao volume, infundir drogas vasopressoras ou inotrópicas, preferencialmente, após as tentativas com reposição volêmica ${ }^{1}$.

É importante ressaltar os cuidados com as medicações prescritas, já que os medicamentos utilizados para o tratamento do quadro neurológico não se fazem mais necessários, e o profissional de enfermagem deve possuir conhecimento adequado para opinar sobre a suspensão de anticonvulsionantes, analgésicos, antitérmicos e diuréticos osmóticos, mantendo somente os antibióticos quando prescritos ${ }^{12,13,14}$.

A manutenção do PD requer a o suporte da ventilação mecânica artificial e aspiração traqueal sempre que necessário, a fim de manter as vias aéreas desobstruídas. A equipe precisa estar atenta ao paciente, tomando cuidado ao movimentá-lo, prevenindo a desconexão do ventilador ou pinçamento do circuito, mantendo as traqueias artificiais livres de contaminantes que possam prejudicar as vias respiratórias. De tal modo, manter adequada ventilação e oxigenação (saturação ideal acima de 94\%), controlando parâmetros do ventilador mecânico, assim como realizar coleta de material para dosagem dos gases sanguíneos e equilíbrio ácido-básico são cuidados essenciais para manter a 
fisiologia respiratória ${ }^{5,15}$.

Verificou-se que o enfermeiro conhece a importância da manutenção da temperatura corporal para o potencial doador de órgãos e também a necessidade de se prevenir complicações que podem contribuir para inviabilizar a doação ${ }^{14}$.

A regulação da temperatura corporal é condição para a manutenção dos processos biológicos que mantém o funcionamento adequado do organismo. Assim, para conservar a viabilidade dos órgãos a serem transplantados deve-se manter a temperatura superior a $35^{\circ} \mathrm{C}$ e inferior a $37,5^{\circ} \mathrm{C}$, com o objetivo de evitar efeitos indesejáveis (coagulopatia, instabilidade hemodinâmica e outros) que podem comprometer a viabilidade dos órgãos a serem ${ }^{7,10}$.

A equipe deve sempre estar vigilante a possíveis alterações relacionadas à diurese, tais como coloração e presença de sangue. Estudos demonstram que o uso da terapia hormonal combinada (insulina, corticoide, hormônio tireoidiano, vasopressina) promove a melhora da estabilidade hemodinâmica e resulta no aumento do número de órgãos captados além da melhor qualidade dos transplantes realizados com esses órgãos ${ }^{16,17,18}$.

Em relação ao aporte energético-calórico, alguns autores descrevem que a falta desse cuidado pode acarretar prejuízo ao metabolismo, por esse motivo é fundamental fornecer equilíbrio hemodinâmico para esse PD. Convém mencionar que a hiperglicemia deve ser controlada, realizando-se dosagens seriadas de glicose sanguínea. Se isto não for possível, o enfermeiro deve orientar a equipe a realizar controle de glicemia capilar, no mínimo, de quatro em quatro horas. Se houver persistência do distúrbio, os intervalos de controle devem ser diminuídos ${ }^{1,16,19}$.

Há necessidade de execução de atividades educativas e de aperfeiçoamento contínuo junto aos profissionais, acerca desse tema, especificando as ações do enfermeiro para a manutenção do PD. Cabe a este ter ciência de todo o processo, além da identificação, confirmação, formalidades legais, prevenção, detecção precocee manuseio imediato das principais complicações advindas da morte encefálica, para que os órgãos possam ser retirados e transplantados nas melhores condições funcionais possíveis. Essas medidas contribuiriam para um cuidado de enfermagem na prática mais qualificada, resultando em condutas profissionais mais uniformes.

Portanto, além de estar atento, o enfermeiro também deverá supervisionar a equipe nos cuidados prestados ao PD de órgãos e tecidos e, para o bom desempenho da equipe, é importante realizar um trabalho educativo e permanente, voltado a capacitar profissionais para conhecer a situação e detectar os problemas que dela podem acontecer, visando planejar e implementar cuidados de enfermagem necessários de forma adequada, avaliando condutas de tratamento do PD.

\section{Considerações finais}

A enfermagem tem enfrentado mudanças que envolvem diferentes aspectos da sua prática, com o avanço tecnológico. Os enfermeiros que atuam em UTIs, têm se deparado com pacientes que, a partir de uma situação traumática, podem progredir para um diagnóstico de ME e tornar-se um PD de órgãos e tecidos. Com esse artigo, foi possível descrever os cuidados de enfermagem para manutenção do $\mathrm{PD}$, e proporcionar ao enfermeiro a importância da qualificação técnicacientífica.

É interessante que o enfermeiro avalie sua ação e execução buscando mais conhecimentos acerca do processo de doação-transplante. Cuidados sistematizados, estratégias de qualificação, cursos de capacitação e atualização constantes devem ser implementados para aperfeiçoar os conhecimentos da equipe, tanto no que se refere aos avanços técnicos quanto, especialmente, no que diz respeito às questões éticas e bioéticas que incidem diretamente no processo de doação e captação de órgãos e tecidos para transplante.

Dentre as perspectivas para estudos futuros espera-se um melhor conhecimento do enfermeiro diante de situações de doação de órgãos. Ao adquirir um profundo conhecimento sobre os cuidados intrínsecos ao procedimento, esse profissional poderá atuar de maneira determinante para o sucesso do processo.

\section{Referências}

1. Westphal GA, Caldeira Filho M, Vieira KD, Zaclikevis VR, Bartz MCM, Wanzuita $\mathrm{R}$ et al. Diretrizes para manutenção de múltiplos órgãos no potencial doador adulto falecido: parte I. Aspectos gerais e suporte hemodinâmico. Rev. Bras. Ter. Intensiva, São Paulo; 2011;23(3):255-268. Available from: https://www.scielo.br/pdf/rbti/v23n3/v23n3a03.pdf.

2. Costa CR, Costa LP, Aguiar, N. A enfermagem e o paciente em morte encefálica na UTI. Rev. Bioética, Brasília, 2016;(24)2:368-373.

3. RBT. Registro Brasileiro de Transplantes. Dimensionamento dos transplantes no Brasil e em cada estado. Ano XXVI, Num. 4 (2011-2018), São Paulo, 2018

4. Brasil. Decreto $n^{\circ} 9.175$ de 18 de outubro de 2017. Regulamenta a Lei $\mathrm{n}^{\circ} 9.434$, de 4 de fevereiro de 1997, para tratar da disposição de órgãos, tecidos, células e partes do corpo humano para fins de transplante e tratamento. Diário oficial da União, 2017; 19 out. Available from: http:// www.planalto.gov.br/ccivil 03/ Ato2015-2018/2017/Decreto/D9175.htm.

5. Vesco NL, Nogueira CS, Lima RF, Souza VN, Brasil BMBL, Viana CDMR. Conhecimento do enfermeiro na manutenção do potencial doador de órgão e tecidos para transplante. Rev. Enferm UFPE. 2016;5(10):16151624. Available from:https://periodicos.ufpe.br/revistas/revistaenfermagem/ article/viewFile/11157/12675.

6. Guetti NR, Marques IR. Assistência de enfermagem ao potencial doador de órgãos em morte encefálica. Rev. Bras. Enferm, Brasília. 2008;61(1):91-97.

7. CFM. Conselho Federal de Medicina. Resolução no 2.173 de 23 de novembro de 2017. Define os critérios do diagnóstico de morte encefálica. Diário oficial da União, 2017, 15 dez. Available from: https://saude.rs.gov.br/ upload/arquivos/carga20171205/19140504-resolucao-do-conselho-federalde-medicina-2173-2017.pdf. 
8. Freire ILS, Mendonça AEO, Pontes VO, Vasconcelos QLDAQ, Torres GV. Morte encefálica e cuidados na manutenção do potencial doador de órgão e tecidos para transplante. Rev. Eletrônic. Enf. 2012;14(4):904-911. Available from: https://www.fen.ufg.br/fen_revista/v14/n4/pdf/v14n4a19. pdf.

9. Mendonça AS, Castro C, Brasileiro ME. Assistência de enfermagem na manutenção do potencial doador de órgãos. Rev. Eletrônic. de Enferm. [serial on-line], 2010;1(1):1-15.

10. Martini M, Fernandes MFO, Martins SA, Nogueira SRGGP. O papel do enfermeiro na manutenção do potencial doador de órgãos. Revista Bras. de Ciências da Saúde. 2008:6(18):35-47. Available from: http://seer.uscs. edu.br/index.php/revista_ciencias_saude/article/view/346\%20.

11. Westphal GA, Garcia VD, Souza RL, Franke CA, Vieira KD, Birckholz VR, et al. Diretrizes para avaliação e validação do potencial doador de órgãos em morte encefálica. Rev. Bras. Ter. Intensiva, São Paulo. 2016;28 (3):220-255. Available from: https://www.scielo.br/pdf/rbti/v28n3/0103507X-rbti-28-03-0220.pdf.

12. Tannure MC, Pinheiro AM. SAE: sistematização da assistência de enfermagem: Guia prático. Rio de Janeiro: Editora Guanabara Koogan Ltda; 2010 .

13. Araujo JPM de, Aguiar VM, Amaral TLM, Genzini T, Prado PR do. Padronização da assistência de enfermagem na manutenção de múltiplos órgãos no potencial doador adulto. Cuid Enferm [Internet]. 2014;8(2):130-6. Available from:http://fundacaopadrealbino.org.br/facfipa/ner/pdf/cuidarte enfermagem_v8_n2_jul_dez_2014.pdf.

14. Guimarães JB, Barbosa NM, Batista M deA, Passos XS. Conhecimento dos enfermeiros sobre condutas na prevenção, manutenção e no controle da temperatura de potenciais doadores de órgãos. J Heal Sci Inst [Internet]. 2012;30(4). Available from: http://www.unip.br/comunicacao/publicacoes/ ics/edicoes/2012/04_outdez/V30_n4_2012_p365a368.pdf.

15. Menna Barreto LN, Chies N, Cabral ÉM, Nomura ATG, Almeida M de A. Síndrome del equilibrio fisiológico deteriorado en potenciales donantes de órganos: identificación de las características definitorias. Enferm glob [Internet]. 2019;18(55):643-60. Available from: http://scielo.isciii.es/scielo. php? script $=$ sci_arttext\&pid $=\mathrm{S} 169561412019000300643 \& \operatorname{lng}=\mathrm{es} \& \mathrm{nrm}=$ iso \&tlng=es.

16. Cavalcante LP, Ramos IC, Araújo MA, Alves MD, Braga VA. Cuidado de enfermagem ao paciente em morte encefálica potencial doador de órgão. Acta Paul Enf. 2014;27(6):567-572. Available from: https://www.scielo.br/ pdf/ape/v27n6/1982-0194-ape-027-006-0567.pdf.

17. Oliveira MJR de L, Morais Júnior SLA de. O enfermeiro x potencial doador de órgãos: conceitos relacionados à religião. Nurs (Säo Paulo) [Internet]. 2015;18(214):950-4. Available from: https://pesquisa.bvsalud. org/portal/resource/pt/lil-789987.

18. Doria DL, Leite PMG, Brito FPG, Brito GMG, Resende GGS, Santos FLLSM. Conhecimento do enfermeiro no processo de doação de órgãos. Enferm foco [Internet]. 2015;6(1/4):31-5. Available from: http://revista. portalcofen.gov.br/index.php/enfermagem/article/view/573.

19. Mcphee S, Hammer G. Fisiopatologia da doença: uma introdução à medicina clínica. Brasil: Editora Artmed; 2015. 